\title{
Complex interactions between biota, landscapes and native peoples
}

\author{
Jose MV Fragoso ${ }^{{ }^{*}}$ and Nicholas J Reo ${ }^{2}$
}

\begin{abstract}
The papers presented here originated with a symposium held at the Ecological Society of America's annual meeting in Portland, Oregon, in 2012. They describe how native people and indigenous researchers view and understand the cultural and biological complexity inherent in coupled socio-ecological systems. The researchers note that interactions between native peoples and their environments consist of a complex network of linkages, feedbacks, and change, and they describe synthetic approaches to problem solving. These approaches often spring from long cultural traditions and recent adaptations to environments. There are examples of native peoples successfully managing biota and ecosystems for thousands of years. Yet, current societal conditions often challenge indigenous-based efforts to continue managing ecosystems and biota. Nonetheless, in the face of the new challenges native people continue to innovate and manage their environments and biota.
\end{abstract}

Why be concerned with indigenous peoples and their environments? After all, these people are few in number and have little influence on the environment. These were the sentiments of a reviewer regarding a funding proposal submitted by one of us to the U.S. National Science Foundation (NSF) in the mid 2000s, expressing a viewpoint that was not uncommon among environmental scientists at the time. We hoped that organizing an oral session at the Ecological Society of America (ESA) annual meeting would help eliminate this type of misconception. We also sought to highlight work on the environment and humans authored by tribal and indigenous researchers. We were relieved when our special session on complexity in indigenous peoples' interactions with the environment was accepted at the 2012 ESA annual meeting. Tribal and indigenous researchers presented six of the seven talks in our session. We were also pleased to learn that ours was one of five sessions focused on indigenous peoples and the environment. It appeared mainstream North American ecologists had come to realize that a key group of ecologists had not been participating in their discussions. This Special Issue arose from the concerns that led us to develop the ESA session; as with that oral session, the majority of papers,

\footnotetext{
* Correspondence: fragoso@stanford.edu

'Department of Biology, Stanford University, Stanford, CA, USA

Full list of author information is available at the end of the article
}

four out of seven, are authored by indigenous researchers and scientists.

Interactions among groups of people, biota, and their concomitant landscapes are inherently complex, making research concerning these relationships challenging. This is particularly true when studying indigenous peoples or other marginalized societies because (1) their land-based practices are often conducted discreetly, (2) these activities may not be recognized by non-indigenous governments or accounted for in their policies [which partly explains point (1)], (3) the interactions occur within specific socio-cultural contexts necessitating cultural competencies for appropriate interpretation of results, and (4) the interactions may occur over long timespans and require the integration of multiple forms of information.

The contributors to this Special Issue find innovative ways of transcending these research challenges. Central to these articles is a discussion of how traditional environmental knowledge (TEK) is defined and utilized by indigenous communities and federal regulatory bodies and how it is impacted by changing environments.

Whyte, in his paper "On the Role of Traditional Ecological Knowledge as a Collaborative Concept: A Philosophical Study," provides an insightful perspective concerning the meaning and function of TEK. He provides the novel insight that TEK should be a viewed as a collaborative concept whose function is to bridge cultural perspectives in cooperative resource management 
or conservation scenarios. He points out that the term TEK is relatively new, including to indigenous and Native peoples. Indigenous resource professionals and harvesters more commonly refer to their relationships with biota and land, or their practices, rather than their "TEK." When they discuss the idea of TEK, it is presented as more of a verb than a noun. Non-indigenous resource professionals are more accustomed to thinking of biological and ecological knowledge as content or fungible information that can be described as an item one acquires through research and practical experiences. Whyte suggests that the concept of TEK can be used strategically to bridge different worldviews and perspectives in the context of resource management and conservation. TEK is then a conceptual area where indigenous and other views can be brought to the discussion of environmental ideas and concerns without fear. In Whyte's view TEK is a "safe place" where people potentially at odds can hold conceptual meetings.

However, Western legal practices often undermine the ability for indigenous communities to utilize TEK. For example, in her paper "Why We Gather: Traditional Gathering in Native Northwest California and the Future of Bio-cultural Sovereignty," Risling Baldy describes how laws and policies of the dominant society can undermine the cultural environmental heritage of indigenous people. Through a contextualized analysis of Lyng v. Northwest Indian Cemetery Protective Association (1988), Risling Baldy shows how the U.S. Supreme Court limited California Indians' ability to conduct land-based cultural practices, impacting their bio-cultural sovereignty. Risling Baldy is Hupa/Yurok/Karuk Indian from California and leverages her personal experiences and TEK to show how Native peoples maintain cultural practices and knowledge despite harmful policy developments such as occurred in the Lyng case. She then demonstrates how decision makers can work closely with indigenous peoples and respect their inherent biocultural sovereignty.

The Lyng ruling is emblematic of a widespread and ongoing approach to natural resource governance that disconnects indigenous people from their spirituality, cultural traditions, and the environment. Once indigenous peoples' resource use and management systems are disrupted, how can they revive important cultural practices and restore associated habitats? Hankins, another indigenous scholar from a California Indian tribe, uses ethnographical methods to develop hypotheses about the effects of California Indian tribes' prescribed burning practices on riparian ecosystems. Similar to Risling Baldy, Hankins' research is informed by TEK. He empirically demonstrated how traditional burning practices improved the diversity and abundance of plant species and enhanced wood structure of the plants used in traditional crafts. This paper fills a research void about fire effects on riparian vegetation and uniquely bases its research hypotheses on local TEK about indigenous habitat management.

Traditional resource management systems like those explored by Hankins are effective in preserving desirable species. However, once a traditionally harvested species gains significant financial value, there exists the possibility that it will be overharvested, causing a collapse of the traditional system. Mandle et al. describe a study of palm-human interactions in India where changing cultural ways appear to have resulted in palm overharvesting. They demonstrate that as indigenous and other local people became more involved in the regional economy, their traditional interaction with the palm species changed and seemed to result in overharvesting. However, Mandle et al. posit that invasion of habitats by an exotic plant species was responsible for the declining harvests, along with social change in the human communities, rather than overharvesting by people. Once again we see how events not directed at indigenous people, in this case invasion by an exotic species coupled with market integration, can unintentionally impact cultural practices.

Anthropogenic change in the natural environment can also disrupt the utilization of TEK. Hoover's paper describes the cultural and physical separation of the Akwesasne Mohawk people from fish and freshwater ecosystems after chemical pollutants from industrial factories were dumped into the St. Lawrence River. This dumping of toxic pollutants led to the U.S. government designating the factory sites a Superfund area. To prevent the poisoning of Tribal members, the government researchers recommended that the Akwesasne Mohawk, especially young people and women of childbearing age, not eat fish since these contained high levels of PCBs and other toxic materials. Most Tribal members followed the recommendation, however this rapid change in diet from fish to highly processed foods exacerbated diabetes and other metabolic conditions in the community. Equally impacted was the relationship Mohawks held with the river, as lack of fishing led to a loss of cultural and linguistic tradition that had linked residents with their environment. This is an example of how regulatory policy has favored affordable remediation over community preservation of traditional environmental knowledge. Thus, Hoover's paper highlights the environmental justice dimensions of environmental disasters when indigenous populations experience disproportionately severe impacts generated by national societies. Policies designed to mitigate environmental disasters can have perverse effects on indigenous peoples when the policies are malformed vis-à-vis culturally 
specific relationships among Native peoples, land, and biota.

Other indigenous communities have worked to adapt TEK to changing environments through hybrid management systems. Lepofsy and Caldwell took on the challenge of understanding indigenous resource management practices over long timescales by conducting an interdisciplinary review of the evidence of ecosystem management by the indigenous peoples of northwestern North America. Through an integrated review of ethnographic and archeological evidence, these authors provide a convincing case that indigenous ethnic groups of the region managed marine and freshwater species and ecosystems for 1,000 years or more before the arrival of Europeans. The physical vestiges left from this management, along with people's oral histories, provide important insights about ecosystem management by indigenous peoples in North America prior to European settlement. Indigenous cultures and environments change as they adapt to novel conditions. Gomes describes how the Lekwungen people of the Tl'chés islands near Victoria, Canada, embraced change in their environment. In their homeland, ecological restoration for cultural landscapes incorporated exotic plant species and other elements of biotic communities with which they had co-inhabited the islands for many human generations. The Lekwungen value both the historical ecological conditions of the Tl'chés islands and present-day novel or hybrid ecological communities; for example, they appreciate the heritage apple and plum trees, and exotic blackberry bushes planted by ancestors or introduced by others. Thus, the present-day communities on the island embody a hybrid management system (traditional and conventional) created by a long history of Lekwungen interactions with the Tl'chés islands.

As environmental calamities continue hovering on the horizon, scientists now embrace views from people previously ignored. As in almost all the studies presented in this special section, key indigenous thinkers were instrumental in leading the development of the hybrid views of culture and the environment presented here. For Gomes, the Lekwungen elder Joan Morris Sellemah, who was raised by her great-grandparents and grandparents on Tl'chés provided the gateway that lead to a novel understanding of ecosystems and culture. Ancestors and elders help indigenous people worldwide link culture to new ways of thinking and living. Our papers seek to guide environmental reasoning in a similar manner, by blending thought on the environment from different cultures and ethical environmental practices. We hope you enjoy our series of papers.
Author details

'Department of Biology, Stanford University, Stanford, CA, USA.

2Environmental Studies Program, Dartmouth College, Hanover, NH, USA.

Received: 24 July 2013 Accepted: 8 September 2013

Published: 27 September 2013

doi:10.1186/2192-1709-2-28

Cite this article as: Fragoso and Reo: Complex interactions between biota, landscapes and native peoples. Ecological Processes 2013 2:28.

Submit your manuscript to a SpringerOpen ${ }^{\circ}$ journal and benefit from:

- Convenient online submission

- Rigorous peer review

- Immediate publication on acceptance

- Open access: articles freely available online

- High visibility within the field

- Retaining the copyright to your article

Submit your next manuscript at $>$ springeropen.com 